
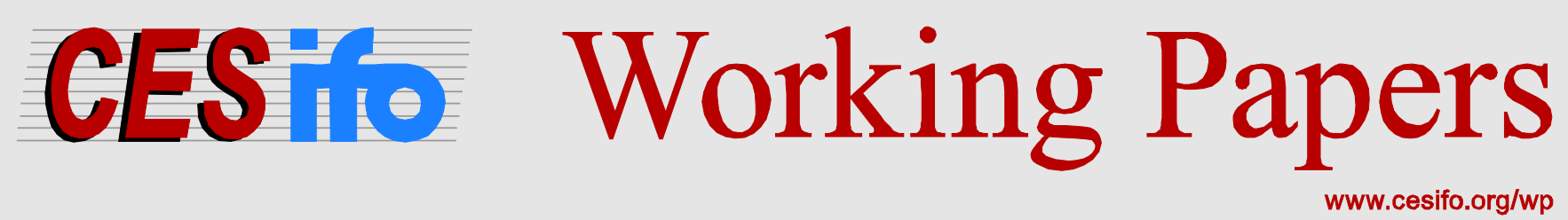

\title{
Going Full Circle: Demand-Side Constraints to the Green Paradox
}

\author{
Corrado Di Maria \\ Ian A. Lange \\ Edwin van der Werf
}
CESIFO WORKING PAPER NO. 4152
CATEGORY 10: ENERGY AND CliMATE ECONOMICS
MARCH 2013
An electronic version of the paper may be downloaded
- from the SSRN website: Www.SSRN.com
- from the RePEc website: Www.RePEc.org
- from the CESifo website: www.CESifo-group.org/wp

\section{CESifo}




\title{
Going Full Circle: Demand-Side Constraints to the Green Paradox
}

\begin{abstract}
We argue that the literature on the green paradox has largely ignored the demand side of the resource market, and that this side of the market may mitigate the size of an emissions increase in response to imperfect climate policies. These claims are informed by recent empirical findings. Our arguments lead to clear policy recommendations.
\end{abstract}

JEL-Code: Q310, Q380, Q580.

Keywords: green paradox, climate policy, demand side response.

\author{
Corrado Di Maria \\ Department of Economics \\ University of Birmingham \\ JG Smith Building \\ B15 2TT Edgbaston, Birmingham \\ United Kingdom \\ c.dimaria@bham.ac.uk
}

\author{
Ian A. Lange \\ Department of Economics \\ University of Stirling \\ $3 B 72$ \\ FK9 4LA Stirling \\ United Kingdom \\ i.a.lange@stir.ac.uk
}

\author{
Edwin van der Werf \\ Environmental Economics and \\ Natural Resources Group \\ Wageningen University \\ 6700 EW Wageningen \\ Netherlands \\ edwin.vanderwerf@wur.nl
}




\section{Going full circle:}

\section{demand-side constraints to the green paradox}

\author{
Corrado Di Maria* \\ University of Birmingham
}

\author{
Ian Lange ${ }^{\dagger}$ \\ University of Stirling
}

Edwin van der Werf ${ }^{\ddagger}$

Wageningen University

\section{Introduction}

In a recent thought-provoking contribution, Hans-Werner Sinn coined the term "Green Paradox" to indicate the possibility that climate policies, such as carbon taxation and subsidies to renewable sources of energy, might induce resource owners to increase fossil fuel supplies in the short run, and hence increase current greenhouse gas emissions and climate damages (Sinn, 2008).

Sinn's argument is that current emission reduction policies share a common focus on the demand side, while ignoring behavioral responses on the part of fossil fuels suppliers. This demand-side focus, which - according to Sinn - is common among policy makers, may prove counterproductive if policies are not at the same time designed to provide correct incentives to resource owners to reduce current supply. Sinn $(2008,2012)$ goes on to suggest alternative supply side remedies to the challenge of climate change that would not

\footnotetext{
${ }^{*}$ University of Birmingham, Department of Economics, JG Smith Building, Edgbaston, Birmingham B15 2TT, United Kingdom, c.dimaria@bham.ac.uk. Di Maria is a CESifo Research Network Associate.

${ }^{\dagger}$ University of Stirling, Department of Economics, 3B72, Stirling FK9 4LA, United Kingdom, i.a.lange@stir.ac.uk. Lange is a CESifo Research Network Associate.

${ }^{\ddagger}$ Wageningen University, Environmental Economics and Natural Resources Group, Wageningen 6700 EW, The Netherlands, edwin.vanderwerf@wur.nl. Van der Werf is a CESifo Research Network Fellow.
} 
suffer from this criticism.

Sinn's work has spawned a large theoretical literature, which discusses numerous mechanisms that might lead to a green paradox. Overall, these contributions present stylized theoretical analyses rather than attempts to assess the policy relevance of the effects suggested by Sinn $(2008,2012)$ and others. Very recently, however, Di Maria et al. (2012a) presented the first study that empirically assesses the emergence of a green paradox. Their analysis focuses on the passing into law of the Clean Air Act Amendments of 1990. The empirical results of Di Maria et al. (2012a) provide mixed evidence as to the empirical relevance of the green paradox hypothesis. More precisely, their study suggests that, while green-paradox-like effects can be observed in time series of coal prices in the US, the data provide little evidence that this change in price lead to an increase in the actual amount of coal used. The authors suggest several reasons why this might be the case, focusing on factors that might limit the ability of resource users to benefit from the price drop.

In a way, then, the debate seems to have now come full circle, pointing to the necessity of taking into account demand factors when assessing the risk of a green paradox. In this chapter, we first present a brief discussion of the literature on the green paradox, and argue that this literature has largely ignored the demand side of the resource market. We next argue that the (potential) magnitude of a green paradox will depend on the characteristics of the demand side. According to the theoretical literature, the magnitude of the green paradox should be determined using data on scarcity rents of exhaustible resources before and after a policy change. Section 3 discusses several reasons why it is hard to follow such an empirical strategy, and then describes the recent findings of Di Maria et al. (2012a) on the potential green paradox effects following the announcement of the cap on sulfur dioxide emissions in the US in the 1990s. We discuss how the demand side of the resource 
market may be constrained in its response to price changes in section 4 . In section 5 , we discuss what these restrictions may imply for the four imperfect climate policy designs that have been studied in the literature on the green paradox. We conclude in section 6 .

\section{Theories of the green paradox and the demand for re- sources}

In his seminal paper, Sinn (2008) observed that current climate policy approaches focus on reducing the demand for fossil fuels, while ignoring the supply side of the fossil fuel market. However, fossil fuels are derived from non-renewable resources and polluting emissions emerge as the result of both the production and the consumption of such fuels. Moreover, both the overall level and the timing of green-house gas emissions matter in determining the extent of climatic change and the costs it imposes on the aggregate economy. Hence, what matters when judging the effectiveness of climate policy is overall time path of extraction of fossil energy sources. If environmental policy reduces future demand for non-renewable resources but does not reduce cumulative supply, the only result will be a lower price for fuels in the short run. Consequently, short term emissions will increase, while the cumulative level will remain unchanged, all else equal. Climate change mitigation policies should to the contrary aim at reducing the discounted value of profits for resource owners in the short term, thereby inducing them to postpone extraction (Hoel and Kverndokk, 1996). Sinn (2008), however, argues that currently implemented demand-side policies would induce an increase, rather than a decrease, in current extraction and may thereby increase current emissions and speed up global warming, a result he termed a green policy paradox or green paradox for short. 


\subsection{Is there really, really a green paradox?}

Sinn's work prompted several authors to study the effects of climate policy on the supply of non-renewable resources using both theoretical and numerical models of resource extraction. An early article on the topic is Gerlagh (2011), which introduces the notions of a weak and a strong green paradox. Gerlagh defines a weak green paradox as an increase in current emissions in response to climate policy, while a strong green paradox occurs when the net present value of cumulative damages from global warming increases. Studying the effects of cheaper low-carbon energy sources, he finds that a green paradox may or may not occur depending on the exact model under scrutiny. For the simplest model, in which marginal extraction costs for the resource are constant over time and independent of the resource stock, he finds that a drop in the price of a perfectly substitutable clean technology (a so-called backstop) will induce both a weak and a strong green paradox. However, he is quick to point out that this result is far from general. When marginal extraction costs are linear in cumulative supply - and assuming a linear demand -, a weak green paradox still occurs but a strong paradox can no longer be found, as the reduction in cumulative supply that follows from the increased competitiveness of the backstop offsets the increase in climate damages arising from the short-term increase in emissions that is common in green paradox models. Finally, Gerlagh (2011) also studies the case where the two energy sources are imperfect substitutes, and marginal extraction costs are constant. In that case a cheaper substitute to fossil energy eats away resource rents and lengthens the period of resource use, without increasing current resource supply, such that also the weak paradox disappears. Similar results have been found by Van der Ploeg and Withagen (2012) and Grafton et al. (2012).

Support for alternative energy sources is not the only type of policy that affects the 
behavior of fossil fuel suppliers. Van der Werf and Di Maria (2012) identify three more classes of policy measures that have been shown in the literature to have the potential to generate a green paradox.

Since it is the profile of discounted instantaneous profits for resource owners that determines their extraction path, a carbon tax that increases over time - like the one recently implemented in Australia (Australian Government, 2012) - may not be sufficient to postpone emissions, a point already made clearly by Sinclair (1992), for example. Indeed, a carbon tax that grows at a rate higher than the discount rate will, in a world with constant marginal extraction costs and in the absence of a substitute fuel, induce an increase in current extraction. Hoel (2011, 2012a) shows, however, that including increasing extraction costs to this simplistic model makes for a larger range of carbon tax growth rates that have the ability to postpone emissions. Additionally, he shows that in the presence of endogenous investment in alternative energy sources, a green paradox may not occur at all provided that extraction costs do not rise too fast in cumulative extraction.

Another type of policy design that might lead to the emergence of a green paradox is the unilateral implementation of demand curbing measures. Indeed, carbon tax policies, and direct measures supporting renewable energy - such as subsidies, feed-in tariffs or renewable energy mandates - are not implemented on a global scale, but rather adopted unilaterally by small groups of countries. While such policies have been widely studied using models without non-renewable resource (see the discussion in section 5 of Van der Werf and Di Maria, 2012), it was only with the emergence of the interest in the green paradox that scholars started to study this type of policy using models with intertemporal resource scarcity. Using a 2-period, 3-country model, Eichner and Pethig (2011) show that the tightening of a unilateral cap in the first period causes a green paradox (i.e. in their 
context, an increase in global emissions in the first period) if the intertemporal elasticity of substitution is sufficiently low, or the demand elasticity for the resource is sufficiently high, or both. The intuition behind this result is straightforward. The tightening of the cap reduces the resource price in both periods as the scarcity rent drops but increases the consumer price of the resource in the country with the unilateral cap. An increase in first-period global emissions occurs only if the non-abating region absorbs more of the resource than the drop in consumption in the abating region, which will only happen if the abating region does not shift too much of its consumption to the (unconstrained) second period and the non-abating region is sufficiently willing to respond to the lower resource price.

Finally, environmental policies in general, and especially climate change mitigation policies, are usually announced some years before they are actually implemented. Indeed, it took more than ten years before first commitment period of the Kyoto Protocol - which was signed in 1997 and came into power in 2005 - started. The US Acid Rain Program was signed into law in 1990, while the first trading phase only started in 1995 , and the full implementation of the programme happened in 2000. Di Maria et al. (2012b) first use a simple model with a single resource and constant extraction costs to show that announcing a policy that is implemented with some delay induces an increase in extraction in the interim period, i.e. the period between announcement and enforcement of the policy, hence giving rise to a green paradox. Furthermore, they show that this result may be amplified in the case of multiple resources that differ in their pollution intensity, as besides the increase in resource use, there may also be a tendency to substitute towards dirtier resources ahead of implementation (see Di Maria et al., 2012b, for the precise conditions under which this effect emerges). Jus and Meier (2012) show that further postponing the 
implementation of the policy, once the announced implementation date is reached, induces a green paradox as well. Finally, Eichner and Pethig (2011) use their 3-country, 2-period model to also study the announcement of a tighter unilateral cap. In their model a green paradox does not occur if the intertemporal elasticity of substitution is sufficiently low or the resource demand elasticity is sufficiently high, or both. In all these cases in fact resource use in the first period does not respond sufficiently to the lower resource price to lead to a paradox.

This brief overview of the green paradox literature indicates that the green paradox emerges rather starkly from traditional models of optimal physical exhaustion of resources, while this type of outcomes become less likely in models where stock dependent extraction costs à la Heal (1976), in the presence of a backstop, lead to economic rather than physical exhaustion. Quite naturally, in this type of models, increased extraction early on in the planning period comes at the cost of a more rapid switch to the alternative source of energy, and hence proves less attractive. As a general point one might consider the latter class of models as more realistic, and conclude that a green paradox becomes less likely with the increasing realism of the analysis. The possibility of a (weak) green paradox as a result of imperfect environmental policies, however, cannot be ruled out on these grounds. The second take-away point from this short review is that none of the authors mentioned above discusses the potential magnitude of green paradox effects. Indeed, the literature has so far only focused on the use of analytical models (both theoretical and numerical) and lacks empirical evidence. The final point is that, apart from recognising the important role of demand elasticities, the literature virtually ignores the demand side of the resource market. For example, the literature discussed above does not make a distinction between different types of fossil fuels beyond their marginal extraction costs. Yet, each type of 
fossil fuel has specific uses: most coal is used to generate electricity, whereas oil is mostly used for transportation (IEA, 2012). This affects the path of extraction both with and without climate policy (Chakravorty and Krulce, 1994; Chakravorty et al., 1997). As a consequence, each type of fuel is subject to different policies. For example, the demand for oil is affected by mandates requiring the blending of biofuels into gasoline, while the relative demand of coal and gas for electricity generation hinges upon the level of carbon prices (either taxes or permit prices) in regions implementing such policies, and the overall demand for electricity generated from fossil fuels depends on subsidies to renewable energy sources.

In the remainder of this section, we argue that the size of the increase in initial extraction and emissions depends strongly on the demand for resources.

\subsection{The demand for resources and the size of the green paradox}

As correctly pointed out by Sinn (2008), currently implemented climate change mitigation policies focus on the reduction of the demand for fossil fuels. In line with current thinking in environmental economics, most such policies are based on market-based instruments, be them tradable emissions permits (as in the case of the European Union Emissions Trading Scheme and the Regional Greenhouse Gas Initiative in the Northeastern United States), carbon taxes (as implemented for example by Sweden, Australia and other countries), or market-based measures supporting alternative energy sources (such as feed-in tariffs, or subsidies to $R \& D$ for clean energy technologies). Since these policies cover neither all emitting sectors of the economy nor all points in time, there is ample scope for the demand side to respond to changes in fossil fuel prices beyond what is envisioned by policy makers. The logical next question, then, is how does the demand for fossil fuels respond 
to changes in fuel prices, across sectors of the (global) economy and over time, following the announcement or implementation of emission reduction policies?

As noted above, in the theoretical literature, with few exceptions, the demand side does not matter for the materialization of a green paradox. In closed economy models, whether a paradox emerges or not is determined by the exact design of the policy, e.g. the growth rate of the carbon tax, or the characteristics of the resource sector, especially the marginal extraction costs of the resource. Resource demand is usually modeled through a concave utility function, or directly using a (possibly linear) demand function. These functions then incorporate both the willingness of the demand sector to respond to lower prices at a given point in time as well as the willingness to shift consumption over time. As long as the demand elasticity along either dimension is positive, resource use will increase in response to a lower user price.

In open economy models, on the other hand, a positive demand elasticity is not sufficient for a weak green paradox. Eichner and Pethig (2011) split the demand for resources into two parts. First, there is a sector that produces the final good using the resource via a strictly concave production technology. Next, consumers in both the abating and the non-abating country have to decide how much of the final good to consume in each period. In this way, the intertemporal elasticity of substitution is separated from the elasticity of demand for the resource. In a multi-country model with abating and nonabating regions, then, it is not sufficient to have a positive demand elasticity in order to get a green paradox in response to a tightening of the first-period cap on the part of the abating region. The reduction in resource demand in the first period in the constrained region could be shifted to either the second period, or to the non-abating region. For a green paradox to materialize (i.e. for global extraction and emissions to increase in the 
first period), the increased first-period resource use in the abating region must more than offset the demand reduction on the other region, thus leading to an emissions leakage rate in excess of $100 \%$. Not only should the demand elasticity in this country be sufficiently high, but also the intertemporal elasticity of substitution should be sufficiently low, or too much extraction would be shifted to the second period for a green paradox to materialize. This discussion suggests that the characteristics of the demand side of the resource market may affect the magnitude of the green paradox. Given that an imperfectly designed policy may induce an increase in initial extraction and emissions, it is both the willingness to absorb additional resources at each point in time (i.e. the demand elasticity) and the willingness to shift resource consumption to earlier points in time (i.e. the intertemporal elasticity of substitution) that determine by how much current resource use increases in response to the demand reduction policy. Numerical results in Grafton et al. (2012) hint in this direction as well. They study the effects of subsidizing alternative energy on the extraction path of a non-renewable resource. They report that the lower the value of the demand elasticity, the smaller is the change in the exhaustion date of the resource stock, and the smaller is the increase in initial extraction.

We now formally show the effect of the demand for resources on the size of the green paradox with a simplified version of the model used in Di Maria et al. (2012b). Competitive resource owners sell their finite resource stock to a consumption sector. We assume that one unit of resource consumption $R$ induces one unit of emissions. However, at time $t=0$ it is announced that from $t=T$ onward a cap will be imposed on emissions. The representative consumer has a constant relative risk aversion utility function:

$$
U(t)=\frac{R(t)^{1-\eta}-1}{1-\eta},
$$


so $1 / \eta$ represents both the intertemporal elasticity of substitution as well as the static elasticity of resource demand. The dynamics of the resource stock $S$ are given by

$$
\dot{S}(t)=-R(t), R(t) \geq 0, S(0)=S_{0}
$$

Climate policy is described as follows:

$$
R(t) \leq \bar{R} \forall t \geq T
$$

that is, emissions arise from resource use, but starting at time $T \geq 0$, they cannot exceed $\bar{R}$. The total stock of emissions initially available in the economy $S_{0}$, is allocated over three periods of extraction - first a period of unconstrained extraction, then a period in which the cap is binding, and finally extraction after the cap has ceased to be binding:

$$
S_{0}=\int_{0}^{T} R(t) \mathrm{d} t+\int_{T}^{T_{H}} R(t) \mathrm{d} t+\int_{T_{H}}^{\infty} R(t) \mathrm{d} t
$$

where $T_{H}$ indicates the (endogenous) instant at which the cap on emissions ceases to be binding. We illustrate the emissions path for the case of an economy that never faces an emissions cap (with initial extraction $\tilde{R}(0)$ ) and for the case of an announced cap in Figure 1. The two paths cross at instant $T_{X}$.

Indicating the utility discount rate with $\rho$, we show in the appendix to this chapter that this can be written as

$$
S_{0}=\frac{\eta}{\rho} R(0)\left(1-\mathrm{e}^{-\frac{\rho}{\eta} T}\right)+\left(\frac{\eta}{\rho}(\ln R(0)-\ln \bar{R}) \bar{R}-T \bar{R}\right)+\frac{\eta}{\rho} \bar{R},
$$

where $R(0)$ is the initial level of extraction after announcement of the cap. Using the 


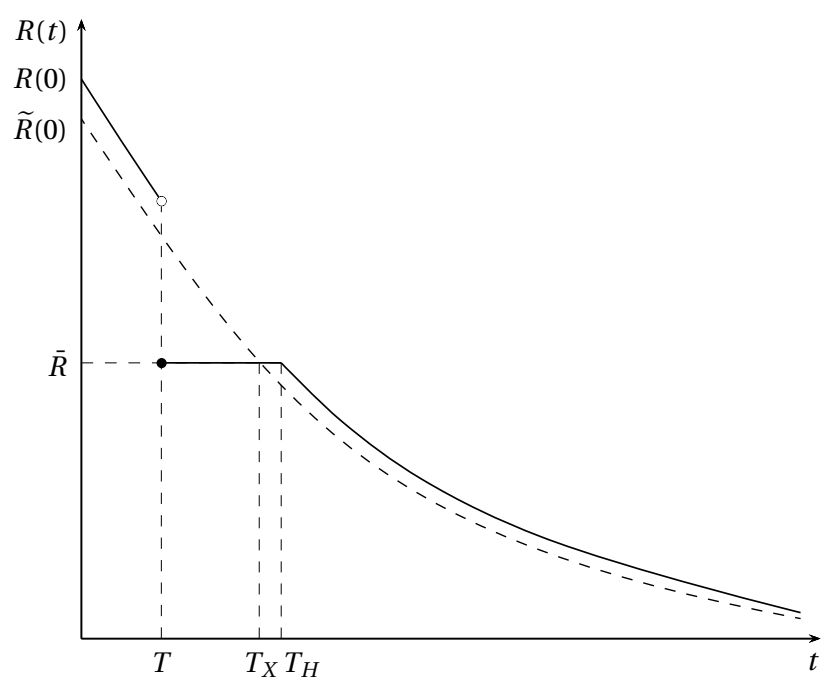

Figure 1: Extraction paths for the laissez-faire economy - dashed line - and for the economy with an announced emissions constraint - solid line.

implicit function theorem, we show in the appendix that

$$
\frac{\mathrm{d} R(0)}{\mathrm{d}(1 / \eta)}=-\frac{\rho\left(T\left(R(0) \mathrm{e}^{-\frac{\rho}{\eta} T}-\bar{R}\right)-\rho S_{0}\right)}{1+\frac{\bar{R}}{R(0)}-\mathrm{e}^{-\frac{\rho}{\eta} T}}>0 .
$$

This shows that the initial level of resource extraction, immediately after announcement of a future cap on emissions, is smaller, the smaller is the demand elasticity for the resource $1 / \eta$

Although it now has been formally shown that restrictions on the demand side matter for the size of the green paradox, we still miss an empirical analysis of the effect of the demand side of the resource market on the size of the green paradox. In the next section we first discuss why it is so hard to carry out an empirical analysis of the green paradox, and then use the results of the only existing empirical study that we are aware of, to argue the importance of the demand side of the resource market. 


\section{Empirical Evidence of a Green Paradox: announcement of the US Acid Rain Program}

Empirically testing whether the green paradox occurs in practice is difficult for many reasons. First, to directly test the green paradox one would ideally obtain mine- or welllevel data on scarcity rents before and after the implementation of a policy (or after its announcement in case of delayed policy implementation). Since scarcity rents are unobservable in practice, however, and given that most extraction firms are vertically integrated, one would need to be able to separate the costs of extraction, milling, refining and other processing that is done before the resource is sold (Krautkraemer, 1998; Slade and Thille, 2009). Because the costs of those processes are usually proprietary information, it is extremely hard to back out those rents from data on reserve sales or resource prices, which usually include such costs (Krautkraemer, 1998; Slade and Thille, 2009).

As always, when the theory is not directly testable, an alternative, albeit indirect way to subject the green paradox to empirical test, is to investigate whether the implications of the theory can be shown to match observable data. In the case of the green paradox, one would need to verify that a decrease in the price of the resource actually materialized after the policy introduction, and that the use of the resource has increased. Moreover, provided there is a differential in the emissions intensity of the resource (e.g. coal vs. natural gas, or different types of coal with different pollution intensities) one could verify whether a switch to the dirtier or lower quality resource has indeed taken place.

A further issue that complicates matters for petroleum, the main resource discussed in the green paradox literature, is that it is traded as a commodity in what is practically a global market. Any policy instituted by one country or small group of countries is 
unlikely to be big enough to alter scarcity rents sufficiently to be observed in the data. Next, establishing causality, i.e. ensuring that any change in behavior found after the policy can be attributed to the green paradox, requires identifying a subset of countries (or firms) that may plausibly be construed as representing the 'control' group in a semiexperimental design. An ideal control group would be countries or firms that are unaffected by the policy, but that are otherwise similar to the 'treated' group. Since, as mentioned, the oil market is a global one, it is unlikely that a control group exists that is unaffected by the policy. ${ }^{1}$ For the purposes of testing a green paradox, it is much more likely that a suitable control group be found for policies affecting coal or natural gas prices, given that most observers consider their markets to be regional.

Another issue in testing the implications of the green paradox (i.e. increased resource use and a switch to the subset of dirtier resources) is whether the resource is consumed by only one sector of the economy. In the case of natural gas - which is broadly used both in power generation and in the residential heating sector - an analysis of the residential heating sector's natural gas consumption after the policy is in effect would have to control for changes in the electricity sector as well, for example.

A final problem that affects the possibility to test the green paradox, regardless of the resource in question, is that testing requires firm- or household-level micro data before and after the policy shock. In many countries, such micro-data either does not exist, is of insufficient quality, or is difficult for researchers to access. The US has a rich set of micro-data for electric power plants over an extended period of time. Both the US and most EU countries have large micro-datasets on households, which include questions on

\footnotetext{
${ }^{1}$ Furthermore, oil is much more linked to macroeconomic outcomes than coal or natural gas, as emphasized by the wealth of literature on oil and the macroeconomy literature (see Hamilton, 2008, for a recent summary) vs. the dearth of coal - or gas - and the macroeconomy literature. Because of this, there are many more general equilibrium effects that would be difficult to disentangle in an analysis of the green paradox that looked at oil consumption reducing policies.
} 
energy use.

Given the long list of caveats listed above, the dearth of empirical analyses on the green paradox is hardly surprising. Indeed, the only empirical test of the green paradox that the authors are aware of is the one in Di Maria et al. (2012a). This paper uses the announcement of the Acid Rain Program in the US, which restricted the emissions of sulfur dioxide $\left(\mathrm{SO}_{2}\right)$ for the last remaining set of unregulated coal-fired power plants in the US, to test whether there was an increase in the use of coal and an increase in the use of higher sulfur coal, following the announcement. ${ }^{2}$ They use plant-level panel data for the price, quantity and quality of coal used by electric utilities in the 1980s and 1990s. Another advantage of this particular policy case study is that the US coal market is and was largely self-contained as only around $2 \%$ of coal transacted was imported or exported. In addition, power plants are by far the largest demander: during the period under scrutiny, they acquired more than $90 \%$ of the coal supplied on the US coal market. As a consequence, a policy shock affecting a large part of the US coal fired power plants would also affect the prices on the coal market and potentially affect the extraction path for this resource. As the data did also provide details on the quality of coal, Di Maria et al. (2012a) are also able to study potential shifts between coal of different $\mathrm{SO}_{2}$ content.

By 1990 power plants that were built during the late 1970s and the 1980s were subject to existing environmental regulation, whereas older plants (known as Phase I plants) were not. The Acid Rain Program was signed into law in 1990 and imposed a cap on the $\mathrm{SO}_{2}$ emissions of Phase I plants from January 1995 onward, while adding (nearly) all other powerplants from 2000 onward. Hence, the signing into law acted as a signal to coal mine

\footnotetext{
${ }^{2}$ Notice that, although this policy is not aimed at mitigating climate change, it definitely has the potential to trigger a green paradox, since it affects the extraction path of a non-renewable resource. Moreover, in terms of both policy design and compliance options, it is a close fit to current climate policy, implying that the results of Di Maria et al. (2012a) are likely to carry over to climate policy.
} 
owners that it would become harder to sell their product in the future, especially for high sulfur mines. Still, Phase I power plants were unregulated in the interim of the regulation of their $\mathrm{SO}_{2}$ emissions so the policy falls into the class of policy designs investigated analytically in Di Maria et al. (2012b): an announced cap on polluting emissions with a time lag between the date of announcement and the date of implementation.

Di Maria et al. (2012a) study the behavior of Phase I plants in the period 1986-1994 and use previously regulated plants as a control group. The latter group was unable to respond to any coal price changes that may have occurred as a result of the announcement of the $\mathrm{SO}_{2}$ cap (due to the type of environmental regulation applied to them), whereas the former group was in a position to benefit from such price changes in the period between the announcement and the implementation of the cap. The authors first use a hedonic price model for the price of coal delivered to power plants to test whether coal prices indeed dropped after the announcement. Next, they utilize a difference-in-difference approach to test how Phase I plants altered their coal consumption relative to non-Phase I plants, after it became clear that a future cap would be implemented. Furthermore, they use a triple difference-in-difference analysis to determine whether market structure or concurrent regulation altered the way unregulated firms responded to the policy announcement.

Di Maria et al. (2012a) find that coal prices were indeed lower after the announcement than before, and that this was even more so for coal with a higher sulfur content: not only did coal mine owners in general face a deterioration of their future market, this was even more so for mines with high sulfur content. This suggests that the 'price part' of the green paradox theories indeed holds. The question, then, is whether these lower prices triggered an increase in coal consumption, and even more so for dirtier coal, in the interim period. The results reveal that the announcement of the policy had no statistical 
impact on coal consumption of Phase I plants as a group. However, using their triple difference-in-difference analysis, the authors are able to identify one group that increased its heat input: Phase I plants that obtained a large share of their input on the spot market. During the 1980s and 1990s, a large share of coal purchased was obtained through longterm contracts, while only 10 to $20 \%$ was purchased on the spot market (Kozhevnikova and Lange, 2009). Still, the percentage of coal purchased on the spot markets varied considerably between utilities, and power plants that were not largely 'stuck' in long-term contracts with previously agreed prices were able to exploit lower prices on the spot market and increased their coal consumption.

Finally, Di Maria et al. (2012a) study how the sulfur content of coal acquired by power plants changed after the announcement of the cap on sulfur dioxide emissions. Contrary to what the green paradox literature predicts, the authors find that the sulfur content of coal decreased. This finding is in line what has been found before in the literature on the US coal market: in anticipation of the implementation of the Acid Rain Program, utilities reduced the sulfur content of their coal in order to comply with the upcoming regulation (Ellerman and Montero, 1998). The authors confirm this finding in their triple differencein-difference analysis, where they find that plants in states that required pre-approval of compliance utilities' plans reduced the sulfur intensity of their coal.

\section{Demand side responses to changes in supply}

The empirical analysis of Di Maria et al. (2012a) shows little evidence of a green paradox in response to the announcement of a cap on sulfur dioxide emissions in the US, despite the drop in coal prices. The additional results in that paper, moreover, hint at potential reasons why the demand side of the resource market may not be very responsive to lower 
resource prices. In what follows, we build on these empirical findings and discuss potential constraints to the ability of firms to take advantage of a drop in the price of fossil fuels.

The first reason why demand responses may be muted is to be found in the nature of the goods and services that fossil fuels are instrumental in providing. The demand for electricity and heating services - both mostly produced by burning coal or natural gas - and for gasoline - which is obtained from the distillation of petroleum - is commonly considered to be very inelastic, especially in the short- to medium-run. For electricity, recent studies such as Lijesen (2007) and Alberini et al. (2011) estimate the short-run demand elasticity to be significantly smaller than one. As a consequence a large fall in the price of electricity is needed in order for a large increase in coal demand to occur. Similar reasoning applies to the use of natural gas for residential heating (Alberini et al., 2011). The demand for gasoline for transport can increase either through an increase in miles driven per car, or through an increase in the number of cars. Both types of demands are quite irresponsive to changes in the price of gasoline, however (Brons et al., 2008). Furthermore, Dargay and Gately (2010) show that the demand for crude oil products (gasoline vs. residual fuel oil) is becoming less price-sensitive over time.

Considering directly the behavior of electricity generators, the responsiveness of coal use (and to a lesser extent of natural gas) to price changes may also be restricted by the structure of the electricity sector. Since there exists a large number of different technologies and fuels that compete on the electricity market to supply electricity, and since their marginal operating costs vary across fuel types, the electricity supply curve is generally well described as a step function. ${ }^{3}$ The lowest step of the supply curve represents the marginal cost of renewables like wind, solar, and hydro, that have very low marginal

\footnotetext{
${ }^{3}$ For an illuminating example of an actual electricity supply curve, see Mansur (2007, p. 668), who uses data from the PJM-interconnector.
} 


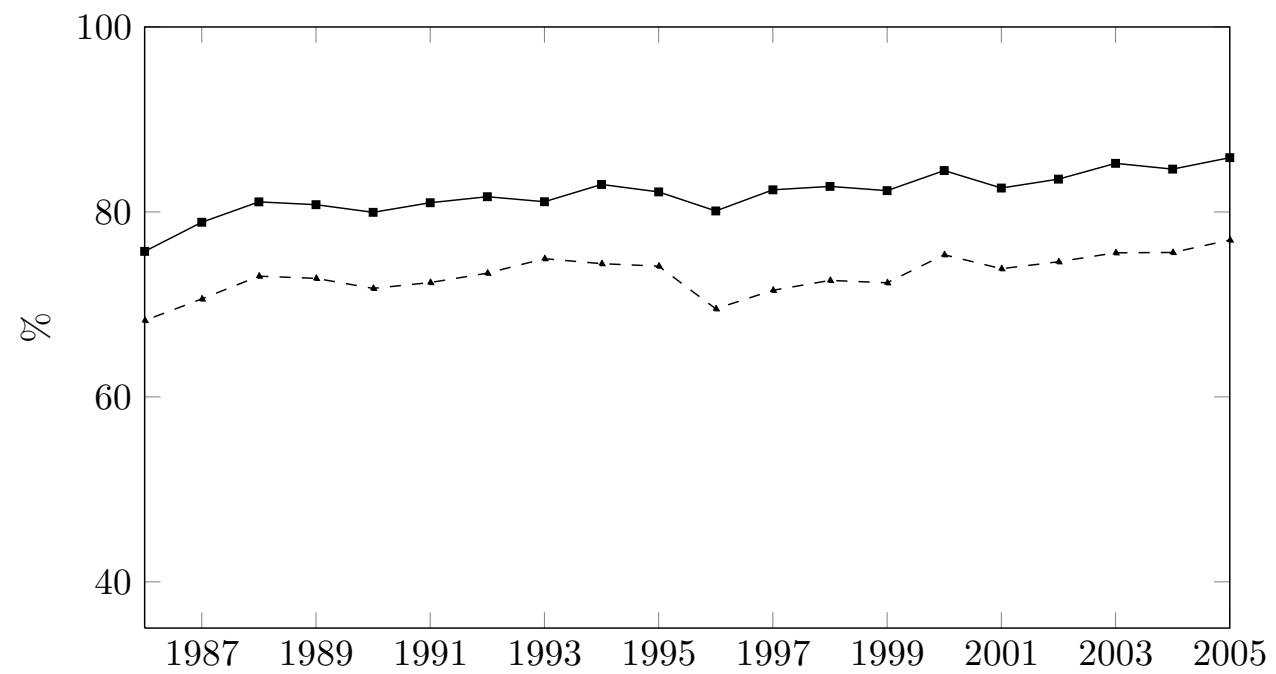

Figure 2: Average (dashed) and median (solid) percentage of the yearly operating capacity of U.S. coal-fired power plants utilized, 1986-2005. Source: Authors' calculations using Energy Information Administration Form 767.

costs. The next step up in the supply function is usually nuclear as it has a very low cost of generation but is extremely complicated to stop and start-up. Next often comes coal, but can be natural gas if the price is low enough. Natural gas is generally easier to ramp-up and down and thus coal tends to be lower on the step than natural gas in most countries. Given this set-up, a decrease in the price of coal may lead it to out-compete natural gas, but it is very unlikely that the price would fall low enough for coal to compete with nuclear. Hence, coal demand by power stations tends to be quite inelastic.

Another point to consider is that, as discussed for example by Bushnell and Wolfram (2005), (coal-fired) power plants enjoy significant returns to scale in production, and achieve their highest fuel efficiency when they are running close to full capacity. As a result, most coal plants run above $80 \%$ of capacity, as can be inferred by the solid line in Figure 2. This implies that capacity is likely to be a significant constraining factor to an increase in demand, at least as refers to base-load power plants and in the short-run. Capacity constraints also seem to impose similar restrictions to gasoline refining. Indeed, data from the U.S. Energy Information Administration show that average refining capac- 


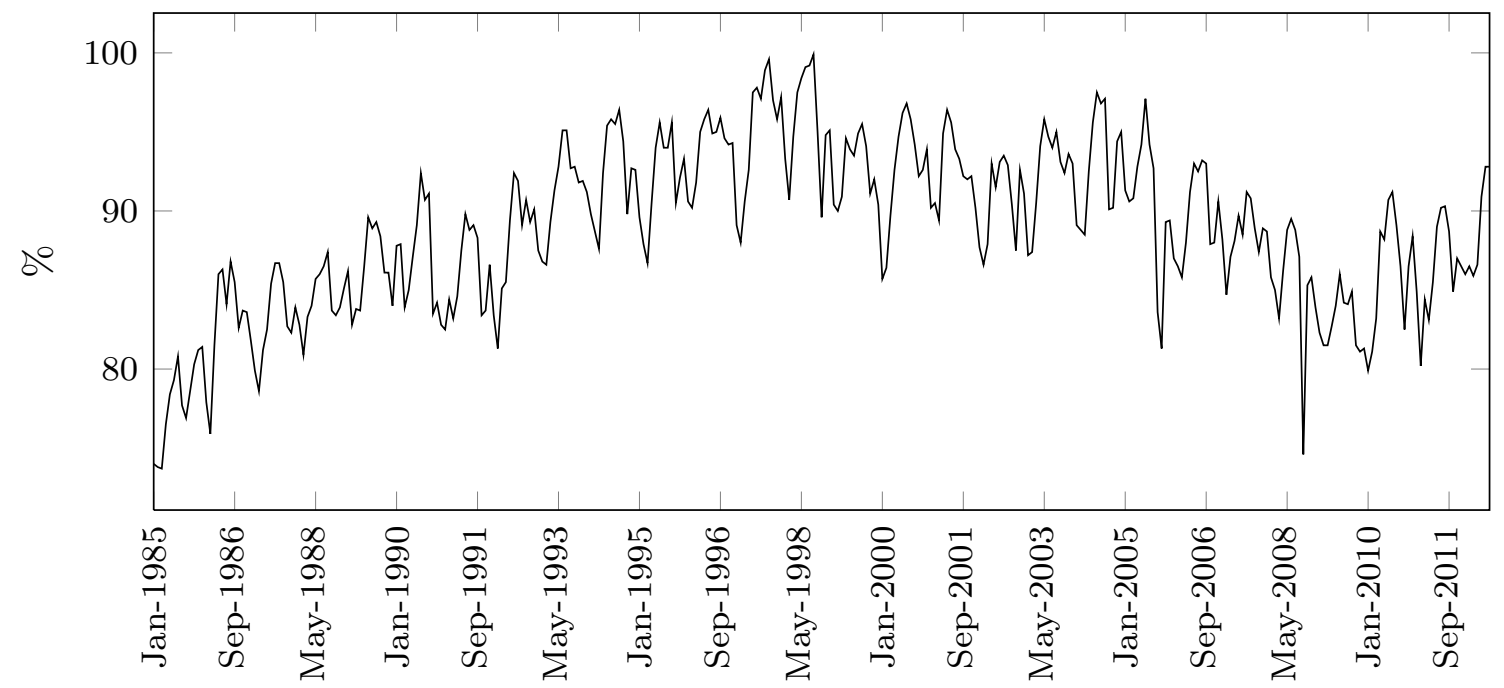

Figure 3: Percentage of the U.S. refining capacity utilized, 1985-2011. Source: Energy Information Administration Monthly, Petroleum Marketing Monthly.

ity utilization between 1985 and 2011 was at 89\%. As a result, short-term increases in gasoline supply may be limited by the availability of refining capacity (see Figure 3 ).

Although capacity may be a restriction on a firm's ability to respond to lower fuel prices, firms may expand their capacity through investment in new capital stock. Still, these investments are very costly and take time to materialize, and hence a firm's cost-benefit analysis will take into account whether there is ample time to get a sufficiently high rate of return on the investment. Given the time it takes to build new capacity, this requires that the period during which the firm can benefit from lower fuel prices is sufficiently long. In case of an announced policy this implies that the implementation lag should be sufficiently long. Indeed, for Phase I plants it was most likely not profitable to invest in new capacity, given that the period between announcement and implementation of the Acid Rain Program only covered some four years.

Yet even when there is sufficient time to make a profitable investment in new capacity, firms may be restricted in their investment behavior by regulatory agencies and local governments. Before a firm can expand capacity on its premises or start building a new 
plant on a newly obtained site, it needs to obtain several licences. In many countries, local governments (e.g. city councils) have to provide planning permission. Even though new plants may generate new employment, 'not in my backyard' attitudes towards emissions to air and water may induce local authorities not to give planning consent (see e.g. Levinson, 1999). In addition, new plants often need to obtain licences from environmental regulatory agencies. For example, the burning of coal produces emissions of particulates, nitrogen oxides, sulfur dioxide, and mercury (among others). These pollutants may be highly regulated, either directly or indirectly through (local) ambient air quality regulations and firms will have to show convincingly that their new capacity will be in line with existing (local) environmental regulations.

Pre-existing environmental regulations will also limit plants ability to increase activity levels increased utilization of existing capacity and in order not to provoke additional monitoring by environmental regulators. For example, coal-fired power plants or oil refineries would have to ensure not to violate pre-existing national or state-level regulations, which restricts them in their ability to increase the total amount of fuel used or its pollution content or both. Indeed, regulated firms tend to be risk averse with respect to compliance. In the Acid Rain Program, many plants operated with a 'self-sufficient' strategy, ensuring that they did not need to purchase permits in the market (Rose, 1997). Indeed, Borenstein et al. (2012) show that regulated natural gas firms are unlikely to make profitable trades when there is concern that regulators may ask questions about the prudence of the decisions.

Similar restrictions hold for the use of petroleum by the transport sector. Many US states and countries have instituted regulations on automobiles to limit the health damages from air pollution. The principally regulated emissions from the transportation sec- 
tor are volatile organic compounds, nitrogen oxides and particulate matter. The United States has National Ambient Air Quality standards for pollutants related to transportation emissions, a host of other on road-specific regulations, as well as state-level regulations (e.g. California's Clean Cars law). To control particulate matter emissions, over 150 cities in 9 European countries have implemented Low Emission Zones (LEZ) (Wolff and Perry, 2010). Any automobile entering a LEZ must be classified as a low particulate matter emitter and these cars are also generally more fuel efficient. In addition, car producers are restricted in the characteristics of the cars they produce, be it through fleet-level policies (Corporate Average Fuel Economy CAFE in the US) or at the vehicle level (Euro 5 vehicle emission standards in the EU).

One final restriction that might limit firms' ability to increase fuel consumption in response to lower fuel prices, and thereby generate a green paradox, stems from the contractual arrangements prevailing in the fuel markets. In the US and EU, coal-fired power plants tend to procure their coal on the basis of long-term forward contracts for two main reasons. The first one being that quantity certainty is important when the plant operates most of the time (base-load plants). There is a large literature concerning the complexity of coal contracts and the risk sharing involved, such as Joskow $(1985,1990)$. The second reason is that coal is of quite heterogeneous quality, and there are costs for a plant if they burn fuel with different characteristics than the boiler was designed for (Crio and Condren, 1984). These costs could be reduced efficiency of the generation process, or more maintenance of the boiler. As a result, long-term contracts are signed to ensure a supply of the optimal type of coal. Deliveries of natural gas are often agreed upon in long-term contracts as well, as suppliers want to make sure that their investment in the pipelines required for deliveries is profitable and hence prefer long-term contracts with their customers (Hirschhausen and 
Neumann, 2008). As mentioned in the previous section, Di Maria et al. (2012a) find that the subset of plants for which a green paradox seemed to have materialized in response to the announcement of the cap on sulfur dioxide emissions under the Acid Rain Program consists of utilities with relatively flexible coal provision arrangements, as indicated by their propensity to purchase coal on the spot market.

While the green paradox literature has largely ignored the demand side of the fossil fuel market, the discussion in this section clearly shows how that side of the market may be constrained in its ability to respond to lower fuel prices through increased fuel demand, and hence higher emissions. Among other things, the inelastic nature of the demand for fossil fuel based energy, pre-existing regulation and the characteristics of the fuel market may all strongly mitigate the potential magnitude of a green paradox.

\section{Demand side restrictions and imperfect climate policy}

How might the demand side restrictions identified above affect the potential magnitude of a green paradox for each of the four imperfect policy designs identified in section 2 ? To answer this question it is important to establish the nature and size of the market that gets affected by the policy.

An important part of greenhouse gas emission reduction policies is aimed at reducing emissions arising from the conversion of fossil fuels into electricity and heat by the power sector. The lessons we derived above from the empirical study of Di Maria et al. (2012a) are directly applicable to these type of policies, and provide important guidance on the likely implication of demand constraints for the emergence of a green paradox. From the discussion in section 2, we know that announcements of a future restriction on emissions, support for alternative energy sources, as well as tax paths that rise 'too fast' all may 
induce responses as identified in the green paradox literature. Yet, as discussed in the preceding section, many power plants would not be in a position to fully exploit the likely fall in scarcity rents that characterizes the green paradox. In countries with pre-existing (environmental) regulation, with low elasticity of demand, and with structural (in terms of both the available capacity, and the competitive and regulatory framework) constraints in the electricity sector, one would expect that the utilities' behavioural responses would be rather muted. Rigidity in supply chains, as e.g. the wide-spread use of long-term contracts for the delivery of fossil fuels, would play a role as well, although the impact of this type of rigidities seems to be diminishing. Indeed, not only did the spot market for coal deepen over time, especially in the US, but also natural gas markets show a clear tendency to globalize as more countries develop reserves of shale gas, and the increasing diffusion of LNG infrastructure makes it easier to ship natural gas across continents.

The single most important type of policy aimed at emission reduction from transport is regulation of the design of new automobiles. Although this type of policy has not been studied explicitly in the green paradox literature, it could induce responses that have been identified in that literature. Automobile regulation is usually announced in advance (CAFE regulation in the US for model years 2017-2025 and Euro 6 standards in the EU), often gets tightened over time, and may include regulation on blending of biofuels or a minimum share of low emission or electric vehicles. If the scale of such regulation is sufficiently large, it may induce resource owners to shift extraction forward in time, resulting in a lower equilibrium oil price. Higher demand for petroleum in response to lower oil prices should come from refineries and the previous section has identified several reasons why this sector is, directly or indirectly, restricted in its response to a lower resource price. Directly, the rate of capacity utilization is usually high, petroleum companies in 
industrialized countries seem to have under-invested in refinery capacity, and it takes considerable time to build a new refinery. Indirect restrictions come from low demand elasticities for gasoline as well as pre-existing regulation.

It is important to note that the policies discussed in this section are all unilateral in nature and mostly implemented by industrialized countries. The unilateral nature of the policies may induce other countries to increase their emissions in response, a mechanism called carbon leakage (see e.g. Eichner and Pethig, 2011; Hoel, 2012b; Van der Werf and Di Maria, 2012), through two channels. First, lower international resource prices, resulting from unilateral demand-reducing policies, may induce countries to increase their resource demand and thereby their emissions. This is called the energy market channel of carbon leakage. Whether global resource prices are affected by unilateral policies depends on the size of the policy and the nature of the resource market. Naturally, if the resource affected by the policy is not traded on a global market, unilateral policy is unlikely to affect resource prices in other countries, and even if the resource is traded internationally in large volumes, both the policy and the country or group of countries affected by the policy should be sufficiently large in order to have a noticeable effect on global resource prices. The second channel of international carbon leakage is the so-called terms-of-trade channel. When the prices of energy-intensive goods produced in countries with climate polices increase - either directly due to a domestic price on greenhouse gas emissions or indirectly through obligatory use of expensive renewable energy technologies - production of such goods may shift towards other countries. To the extent that these countries are industrialized countries themselves, firms in these countries may be restricted in their ability to increase emissions due to reasons explained above. As we will argue below, firms in developing countries may have more scope to increase their emissions. 
In addition to incentives through the energy market channel and terms-of-trade channel of carbon leakage, firms in developing countries may face incentives to increase their emissions in response to domestic policies. Indeed, as policy-makers in developing countries start to introduce demand reducing policies for fossil fuels, they may induce a green paradox themselves insofar these policies suffer from the imperfections discussed in section 2 .

To what extent firms in developing countries are restricted in their ability to increase emissions is largely an open question. In terms of lower fossil fuel prices, demand elasticities for electricity and gasoline are likely to be low in both industrialized and developing countries, although the exact size of these elasticities for developing countries is still quite unknown. A greater potential for an increase in emissions from developing countries may therefore come from increased production for the export market. Restrictions on production through pre-existing regulation, especially environmental regulation, are likely to play a much smaller role in developing countries than in industrialized countries. Capacity expansions are easier to implement when policy makers value (development through) job creation over environmental amenities. Lower relative prices for energy intensive goods from developing countries (through the terms-of-trade channel of carbon leakage or through domestically induced green paradoxes in these countries) may induce demanders of such goods to shift to goods produced in developing countries. Depending on the country under scrutiny, it may not be pre-existing environmental regulation that restricts such expansion of production but (lack of) openness to trade and security of energy or electricity supply. It should be noted, however, that such a shift to production from developing countries may come along with a transfer of clean technologies, which in turn mitigates the potential size of a green paradox (Di Maria and Van der Werf, 2008). Similarly, increased demand for transport in developing countries due to lower fuel prices may be partially 
offset by increased use of cleaner cars. As the automobile market in developing countries is dominated by western (including Japanese) manufacturers and since economies of scale play an important role in this market, it is unlikely that these manufacturers will develop dirtier but cheaper models for sale in emerging economies.

\section{Discussion}

In this chapter, we have argued that the literature on the green paradox has largely ignored the demand side of the resource market, and that this side of the market may mitigate the size of an emissions increase in response to imperfect climate policies. We have supported these claims using the recent empirical findings of Di Maria et al. (2012a) on the response of US coal fired power plants to the drop in coal prices after announcement of the cap on sulfur dioxide emissions in 1990. Furthermore, we have argued that similar restrictions exist for the response of the demand for petroleum after a drop in the price of oil. Finally we have identified emerging economies as potentially the biggest threat to the ineffectiveness of greenhouse gas emission reducing policies.

What lessons can we draw for policy makers? The first and obvious advice would be to repair current emission reduction policies and thereby reduce the potential for a green paradox. However, vested interests and lobbying make it hard for policy makers to simply set an emissions price that reflects marginal damages (not to mention the large uncertainties surrounding the social price of carbon, see e.g. Tol, 2009). In addition, a large part of the response to demand reducing policies may occur in countries that did not implement those policies which shows the importance of including as many countries as possible in an international agreement to reduce greenhouse gas emissions. Unfortunately, recent international conferences on the topic do not give much reason for optimism. Im- 
posing border carbon tariffs on imports from other countries may be effective in reducing potential carbon leakages but may be hard to implement (Böhringer et al., 2012).

The case study of Di Maria et al. (2012a) suggests few potential policies to prevent a green paradox from domestic emission sources. US power plants located in states with strict pre-existing policies, especially policies that required pre-approval of compliance plans of the announced policy, were less able to exploit lower coal prices. If a domestic demand reducing policy specifies milestones or asks the regulated firms to submit compliance plans in advance of the policy's implementation, a green paradox seems less likely to occur. Other restrictions on firms in the case study seem to have stemmed from factors beyond a policy-maker's control (at least on competitive markets). Clearly, more research on potential demand-side responses to emission reduction policies as well as on potential responses by policy makers is necessary.

\section{References}

Alberini, A., W. Gans, and D. Velez-Lopez (2011) 'Residential consumption of gas and electricity in the U.S.: The role of prices and income.' Energy Economics 33, 870-881

Australian Government (2012) 'An overview of the Clean Energy Legislative Package.' accessed through www.cleanenergyfuture.gov.au on October 25, 2012

Böhringer, C., B. Bye, T. Fæhn, and K.E. Rosendahl (2012) 'Alternative designs for tariffs on embodied carbon: a global cost-effectiveness analysis.' Energy Economics

Borenstein, S., M. Busse, and R. Kellogg (2012) 'Career concerns, inaction, and market inefficiency: Evidence from utility regulation.' Journal of Industrial Economics 60(2), 220- 
Brons, M., P. Nijkamp, E. Pels, and P. Rietveld (2008) 'A meta-analysis of the price elasticity of gasoline demand. A SUR approach.' Energy Economics 30(5), 2105-2122

Bushnell, J., and C. D. Wolfram (2005) 'Ownership change, incentives and plant efficiency: The divestiture of U.S. electric generation plants.' University of California at Berkeley Center for the Study of Energy Markets WP 140

Chakravorty, U., and D. L. Krulce (1994) 'Heterogenous demand and order of resource extraction.' Econometrica 62(6), 1445-1452

Chakravorty, U., J. Roumasset, and K. Tse (1997) 'Endogenous substitution among energy resources and global warming.' Journal of Political Economy 105(6), 1201-1234

Crio, M., and A. Condren (1984) 'Which coal at which cost?' Public Utilites Fortnightly $113(16), 32-36$

Dargay, J. M., and D. Gately (2010) 'World oil demands shift toward faster growing and less price-responsive products and regions.' Energy Policy 38, 6261-6277

Di Maria, C., and E. Van der Werf (2008) 'Carbon leakage revisited: Unilateral climate policy with directed technical change.' Environmental and Resource Economics 39, 5574

Di Maria, C., I. Lange, and E. Van der Werf (2012a) 'Should we be worried about the green paradox? Announcement effects of the acid rain program.' CESifo Working Paper 3829

Di Maria, C., S. Smulders, and E. Van der Werf (2012b) 'Absolute abundance and relative scarcity: environmental policy with implementation lags.' Ecological Economics 74, 104119 
Eichner, T., and R. Pethig (2011) 'Carbon leakage, the green paradox and perfect future markets.' International Economic Review 52(3), 767-805

Ellerman, A. D., and J.-P. Montero (1998) 'The declining trend in sulfur dioxide emissions: Implications for allowance prices.' Journal of Environmental Economics and Management 36(1), 26-45

Gerlagh, R. (2011) 'Too much oil.' CESifo Economic Studies 57(1), 79-102

Grafton, R. Q., T. Kompas, and N. V. Long (2012) 'Substitution between biofuels and fossil fuels: is there a Green Paradox?' Journal of Environmental Economics and Management

Hamilton, J. (2008) 'Oil and the macroeconomy.' In New Palgrave Dictionary of Economics, 2nd Edition, ed. S. Durlauf and L. Blume (Palgrave McMillan Ltd.)

Heal, G. (1976) 'The relationship between price and extraction cost for a resource with a backstop technology.' The Bell Journal of Economics 7(2), 371-378

Hirschhausen, C., and A. Neumann (2008) 'Long-term contracts and asset specificity revisited: An empirical analysis of producerimporter relations in the natural gas industry.' Review of Industrial Organization 32(2), 131-143

Hoel, M. (2011) 'The green paradox and greenhouse gas reducing investments.' International Review of Environmental and Resource Economics 5(4), 353-379

- (2012a) 'Carbon taxes and the green paradox.' In Climate change and common sense: essays in honor of Tom Schelling, ed. R.W. Hahn and A. Ulph (Oxford University Press) chapter 11

_ (2012b) 'The supply side of $\mathrm{CO}_{2}$ with country heterogeneity.' Scandinavian Journal of Economics 113(4), 846-865 
Hoel, M., and S. Kverndokk (1996) 'Depletion of fossil fuels and the impacts of global warming.' Resource and Energy Economics 18, 115-136

IEA (2012) 'Key world energy statistics, 2012 edition.' Technical Report, International Energy Agency

Joskow, P. (1985) 'Vertical integration and long-term contracts: The case of coal-burning electric generating plants.' Journal of Law, Economics, \& Organization 1(1), 33-80

_ (1990) 'The performance of long-term contracts: Further evidence from coal markets.' RAND Journal of Economics 21(2), 251-274

Jus, D., and V. Meier (2012) 'Announcing is bad, delaying is worse: Another pitfall in well-intended climate policy.' CESifo working paper 3844

Kozhevnikova, M., and I. Lange (2009) 'Determinants of contract duration: Further evidence from coal-fired power plants.' Review of Industrial Organization 34(3), 217-229

Krautkraemer, J. A. (1998) 'Nonrenewable resource scarcity.' Journal of Economic Literature 36(4), 2065-2107

Levinson, A. (1999) 'NIMBY taxes matter: the case of state hazardous waste disposal taxes.' Journal of Public Economics 74(1), 31-51

Lijesen, M. G. (2007) 'The real-time price elasticity of electricity.' Energy Economics $29(2), 249-258$

Mansur, E. T. (2007) 'Do oligopolists pollute less? Evidence from a restructured electricity market.' Journal of Industrial Economics 55(4), 661-689

Rose, K. (1997) 'Implementing an emissions trading program in an economically regulated industry: Lessons from the $\mathrm{SO}_{2}$ trading program.' In Market Based Approaches 
to Environmental Policy: Regulatory Innovations at the Fore, ed. R. F. Kosobud and J. Zimmerman (New York: Van Nostrand Reinhold)

Sinclair, P. (1992) 'High does nothing and rising is worse: carbon taxes should keep declining to cut harmful emissions.' The Manchester School LX(1), 41-52

Sinn, H.-W. (2008) 'Public policies against global warming.' International Tax and Public Finance 15(4), 360-394

_ (2012) The Green Paradox: A Supply-Side Approach to Global Warming (Cambridge, MA: MIT Press)

Slade, M. E., and H. Thille (2009) 'Whither Hotelling: Tests of the theory of exhaustible resources.' Annual Review of Resource Economics 1(1), 239-259

Tol, R.S.J. (2009) 'The economic effects of climate change.' Journal of Economic Perspectives $23(2), 29-51$

Van der Ploeg, F., and C. Withagen (2012) 'Is there really a Green Paradox?' Journal of Environmental Economics and Management

Van der Werf, E., and C. Di Maria (2012) 'Imperfect environmental policy and polluting emissions: the Green Paradox and beyond.' International Review of Environmental and Resource Economics 6(2), 153-194

Wolff, H., and L. Perry (2010) 'Trends in clean air legislation in Europe: Particulate matter and low emission zones.' Review of Environmental Economics and Policy 4(2), 293-308 